\title{
After repair of tracheo-oesophageal atresia
}

Despite surgery for short gap tracheo-oesophageal atresia and fistula as a baby, a doctor describes how she suffered associated cough and illness throughout childhood and as a student before receiving the diagnosis and care she needed to manage her symptoms

\author{
Caroline Love specialty doctor in dermatology ${ }^{1}$, Alyn $\mathrm{H}$ Morice professor of respiratory medicine ${ }^{2}$ \\ ${ }^{1}$ York District Hospital, York, YO32 9FT, UK; ${ }^{2}$ Cardiovascular and Respiratory Studies, Respiratory Medicine, Castle Hill Hospital, Cottingham HU16 \\ $5 J Q, U K$
}

This is one of a series of occasional articles by patients about their experiences that offer lessons to doctors. The BMJ welcomes contributions to the series. Please contact Peter Lapsley (plapsley@bmj.com) for guidance.

When my first feed in hospital resulted in coughing, choking, and going blue, it was evident that I couldn't swallow. I was quickly transferred to a larger hospital and short gap tracheo-oesophageal atresia and fistula was diagnosed. At the time (1975), although repair of this condition had first been performed in 1948, survival was far from guaranteed. However, despite needing a thoracotomy and trans-sternal incision, the repair was successful, and I left hospital three months later, supposedly cured.

\section{The "cure"}

Although I was the first child of my young parents, they quickly realised I wasn't normal. I slept very badly, choked, and constantly coughed and was irritable and unwell most of the time. Thus began my mother's frequent visits to general practitioners and (initially) paediatric surgeons. Because I was a normal weight, doctors assumed my mother was simply overprotective owing to my initial defect. In addition, my lungs were always clear, so no infection was evident. The one concession to the frequent visits was the diagnosis of reflux, but at this time, Gaviscon was the only option.

In between visits to the doctor, my mother had to cope with having a child with a near constant "TOF cough": the TOF (tracheo-oesophageal fistula) cough is a result of tracheobronchomalacia and tracheal scarring, and sounds like a seal barking. My mother was often accosted by strangers chiding her for taking a child with obvious whooping cough out in the streets, and people pointed and stared.

Despite the ungodly noises coming out of the child in front of them, the doctors continually told us there was nothing wrong with me, and no need for any investigations or treatment.
Ignoring my frequent absences from school (I missed at least two weeks each term) due to "chest infections" and the sequelae of prolonged coughing (black eyes owing to petechial haemorrhage, torn intercostals, and frequent haemoptysis), the doctors did not acknowledge that I had any problem.

\section{A closed mind}

By my late teens, I had internalised the unspoken message of the consultations with doctors. I believed that I was a hypochondriac or simply not as stoical as others and that this explained my frequent absences from school and medical school. Even when I questioned a paediatric surgeon at medical school about whether there was any long term impact of TOF, I was again told there were none.

My mind became closed to any suggestion of disease. Once I started working as a doctor, colleagues suggested there might be a problem, but I could not acknowledge it in the light of my past experiences. When I was a house officer on call, my senior house officer threatened to admit me as my oxygen saturation levels were $92 \%$, but I shrugged it off as a joke. A doctor housemate complained I kept her awake all night coughing, but as I slept fine, I thought she was over-reacting. It was not until my consultant and the occupational health doctor insisted on a respiratory opinion when I was 30 (after I had had four "chest infections" in four months) that I was forced to accept there might be a problem.

\section{Looking for answers}

My first respiratory history revealed how deeply in denial I was about the problem. It had not occurred to me that others do not cough every day, cough up sputum daily, or suffer "infections" as frequently as I did. A range of investigations revealed severe tracheobronchomalacia and a fluid filled pouch at the base of the trachea. At this point I was referred to the Liverpool 
cardiothoracic unit. Further investigation there showed poor oesophageal motility, that my trachea, oesophagus, and aorta were stuck together, and my lungs were completely normal. However, I was getting sicker and sicker as each investigation exacerbated my chest problems.

\section{Cognitive dissonance}

The discovery that I did have a real health problem had a major psychological impact on me. I was extremely angry. I was angry first at my senior colleagues for making me face up to the truth, and then at all the doctors who had treated me in the past. I was angry at the doctors not because they had not known what to do, but because they were too arrogant to admit their ignorance and seek further information, instead blaming my family and me for the problem. No one could expect a GP to know what the long term outlook of this new patient group would be, but in refusing to accept there might be one, they failed me. The cognitive dissonance that this anger caused was hard to deal with. On one hand I was a hospital doctor treating patients, but on the other, I resented the medical profession and the attitudes that had brought me to this point. I also grieved for the child I had been - the breathless toddler learning to speak quietly and quickly in between coughs, the schoolgirl bullied for my coughing, and the teenager cancelling social events owing to ill health.

\section{Finding answers}

Although the doctor at the Liverpool cardiothoracic unit had begun to improve things for me, the real turning point came when I moved to Yorkshire. I was referred to Professor Morice's cough clinic. The first sign of what was to come was the reflux severity index I completed on arrival. I quickly realised I scored highly on all counts. When this was followed by a consultation in which my condition was both understood and explained, and a treatment plan devised, I felt hope for the first time in many months. I learnt that my "chest infections" were episodes of aspiration, hence their unresponsiveness to steroids, and my other symptoms were manifestations of gastro-oesophageal reflux. I was started on a range of medications, to see what would control the symptoms, and I have found a regimen that keeps things settled. I am still learning about my condition-at a recent conference I learnt that the reason for my frequent choking episodes is that in people with a tracheo-oesophageal fistula the pharynx may also be dysfunctional, resulting in an unsafe swallow. Such information doesn't alter anything but helps me understand my problems better. As I've improved, I realise I am luckier than many with my symptoms, most of which come from an irritant tracheitis, which has prevented deeper damage, but others in similar situations develop chronic obstructive pulmonary disease or bronchiectasis.

Competing interests: Both authors declare no support from any organisation for the submitted work; no financial relationships with any organisations that might have an interest in the submitted work in the previous three years, no other relationships or activities that could appear to have influenced the submitted work.

Provenance and peer review: Not commissioned; not externally peer reviewed.

Accepted: 15 December 2011

Cite this as: BMJ 2012;344:e3517

(c) BMJ Publishing Group Ltd 2012 


\section{What this has taught me}

As a doctor

- Patients prefer to hear "I don't know" to unfounded explanations or reassurances

- It is not a professional failure to seek advice from other doctors who may know more

- It cannot be underestimated how rude people can be about differences, visible (such as rashes and marks) or otherwise. Strangers, friends, and family may be culprits, even if well meaning. This has been invaluable experience for my work in dermatology

- The medical profession is not good at accepting and dealing with sick colleagues-there is an unwritten rule that doctors are not allowed to be ill

- People with lifelong chronic disease become institutionalised; this may be through becoming a medic or through medical attention-seeking behaviour

- Patients with rare diagnoses also get common problems

As a patient

- Be your own expert patient-my treatment as a patient improved immeasurably once I added MBChB after my name, and I understand my health better than most GPs

- Having a rare and poorly understood condition is difficult to live with and to explain to others

- Clear boundaries are essential for staying well and being able to work-pacing oneself and not agreeing to extra work is essential (I'm still working on that one)

- My biggest struggle has been to accept that I have only limited control of my health, and am not to blame if it deteriorates, but at the same time I must take appropriate measures to protect it

- There are benefits to having been left to fend for myself healthwise for many years. Because I was "cured," there was an expectation I should achieve academically and get a job. I'm not sure I would have achieved as much if there was an excuse not to

\section{A doctor's perspective}

Chronic cough is a common but neglected symptom. In the 19th century its origin was suggested to be a form of reflux, and it is only recently that irritation by a gaseous, non-acid, mist has been shown to cause exquisite hypersensitivity of the upper airways. When aspirated, this reflux can give rise to wheezing, leading to the mistaken diagnosis of asthma, and consequent lung damage leads to many other respiratory conditions, such as bronchiectasis, exacerbations of chronic obstructive pulmonary disease, and even pulmonary fibrosis. No objective tests reliably detect the cough hypersensitivity syndrome, but the clinical history of associated features is characteristic. A validated questionnaire (available at www.issc.info) allows the identification of airway reflux as the cause of otherwise mysterious respiratory and upper airway symptoms.

"TOF" (derived from tracheo-oesophageal fistula) is a generic term for a variety of congenital abnormalities of the trachea and oesophagus. Embryologically the lungs are a mere "out-pouching" of the gut. Most patients present in the neonatal period with choking attacks associated with feeding. Pioneering surgery developed in the 1960 s and '70s corrected the anatomical defects and the patient was apparently "cured." However, the oesophagus is an extremely complex organ, which not only conveys the food into the stomach but is also responsible for the retrograde transport of excessive gas. The delicate physiology of this biphasic movement remains disordered in the overwhelming majority of patients with TOF. This leads to recurrent episodes of non-acid reflux and aspiration. In the very active patients' association TOFS, this is known as TOF cough. Because many operations have been performed over the years in our cardiothoracic centre, I have seen many such patients and, indeed, have been labelled as the Prof of TOF cough.

Unlike for patients with simple chronic cough, for patients with TOF cough, imaging such as barium studies may be rewarding, delineating the large dilated sections of oesophagus or colonic transposition, which develop after surgery. Mechanical approaches, such as dilation or myotomy can then be helpful. As in chronic cough, drug treatment is targeted at enhancing motility and relieving any oesophagogastric obstruction. Promotility agents such as the dopamine agonists, metoclopramide, and domperidone may help. The GABA ( $\gamma$-aminobutyric acid) agonist baclofen can, by enhancing lower oesophageal tone, prevent frank gastroesophageal reflux. The macrolide antibiotics, erythromycin and azithromycin, act as agonists of the hormone motilin, enhancing the poor peristalsis; hence, their activity in other respiratory conditions such as exacerbations of chronic obstructive pulmonary disease and cystic fibrosis. Finally, trazodone acts via 5 - $\mathrm{HT}_{2}$ receptors to enhance oesophageal transit.

For intractable coughing, low dose morphine can in some patients bring significant relief, and the dexbrompheniramine component of some combination antihistamine preparations is an antagonist of the TRPV1 cough receptor. Cough suppression, however, must be used cautiously since a cough is primarily a protective reflex against aspiration and the clinician must balance symptom relief against possible increase in end organ damage.

Alyn $\mathrm{H}$ Morice, professor of respiratory medicine

\section{Resources for patients and clinicians}

- TOFS ()-A UK based charity providing emotional support to families of children born with tracheo-oesophageal fistula (TOF), oesophageal atresia, and associated conditions. The site also links to a range of European TOF groups in other languages

- ea/TEF (Esophageal Atresia/Tracheoesophageal) Child and Family Support Connection ()—A US non-profit organisation supporting families and educating them and medical professionals about the condition

- OARA (Oesophageal Atresia Research Auxillary) ()-An Australian support group based at the Royal Children's Hospital, Melbourne that supports families, organises research into the condition, and funds specialist nurses

- Living With Reflux ()—A UK based support group for families with children with severe gastro-oesophageal reflux disease

- PAGER (Pediatric/Adolescent Gastroesophageal Reflux Association) (www.reflux.org ) -A US non-profit organisation offering advice and support for families with a child with gastro-oesophageal reflux disease 